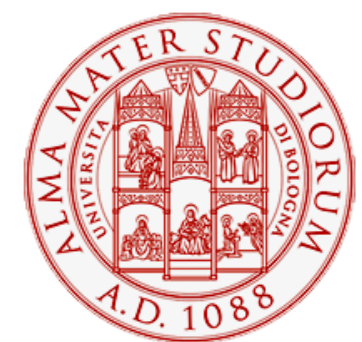

Alma Mater Studiorum - Università di Bologna DEPARTMENT OF ECONOMICS

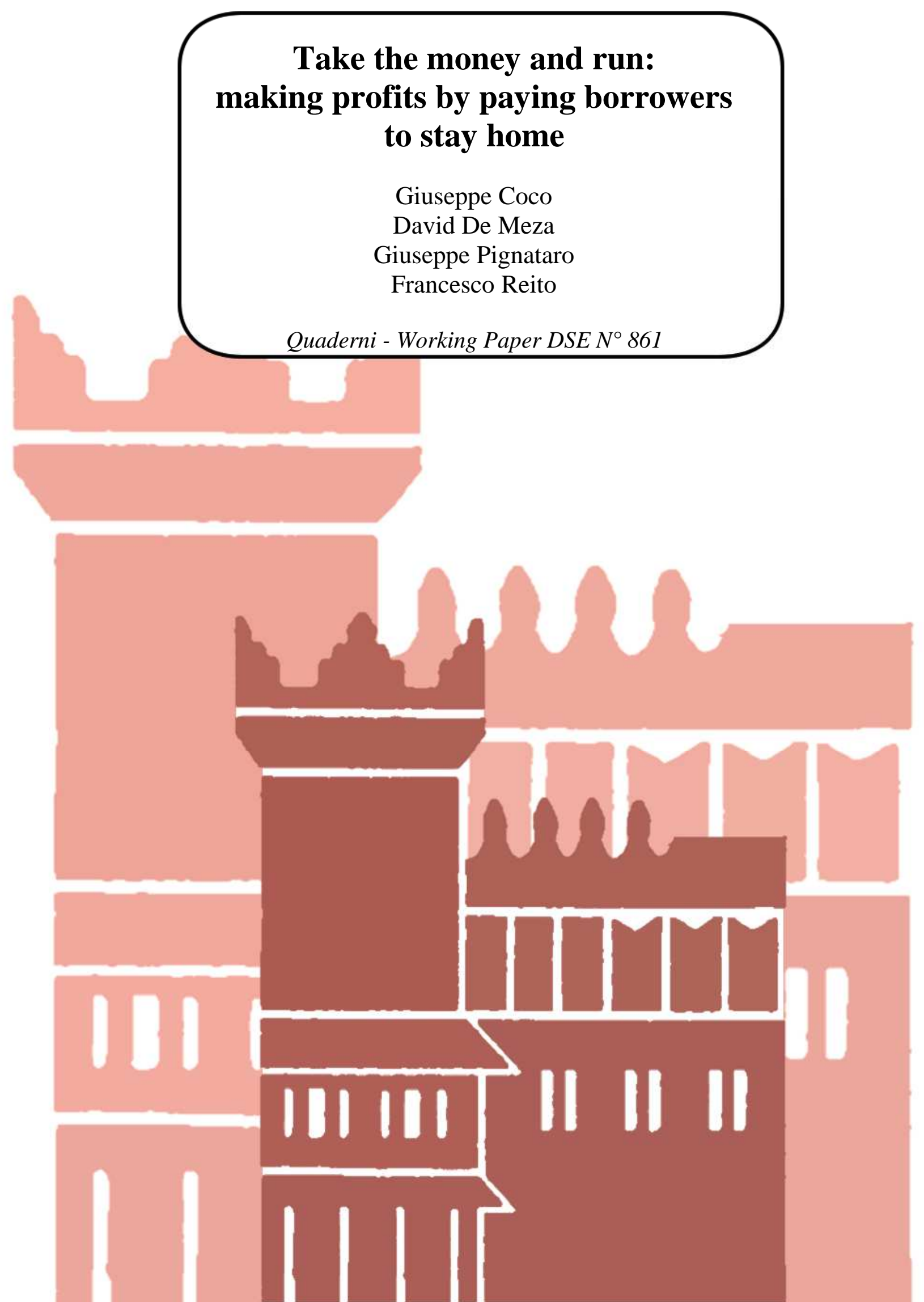




\title{
Take the money and run: making profits by paying borrowers to stay home
}

\author{
Giuseppe Coco* \\ David De Meza ${ }^{\dagger}$ \\ University of Florence \\ London School of Economics \\ Giuseppe Pignataro \\ Francesco Reito ${ }^{\S}$ \\ University of Bologna \\ University of Catania
}

January 2013

\begin{abstract}
Can a bank increase its profit by subsidizing inactivity? This paper suggests this may occur, due to the presence of hidden information, in a monopolistic credit market. Rather than offering credit in a pooling contract, a monopolist bank can sort borrowers through an appropriate subsidy to inactivity. Under some conditions, sorting may avoid the collapse of the market and increases the welfare of everybody. The bank increases its profits, good borrowers benefit from lower interest rates and bad potential borrowers from the subsidy. The subsidy policy however implies a cross subsidy between contracts and this is possible only under monopoly.

Keywords: Credit market, Screening, Subsidy

JEL classification: D60; D82; H71

${ }^{*}$ Dipartimento di Studi sullo Stato, University of Florence. Email:

$\dagger^{\dagger}$ Department of Management, London School of Economics, London, UK. E-mail: d.de-

${ }^{\ddagger}$ Department of Economics, University of Bologna, Bologna, Italy. E-mail: giuseppe.pignataro@unibo.it

${ }^{\S}$ DEMQ, University of Catania, Catania, Italy. E-mail: reito@unict.it
\end{abstract} giuseppe.coco@unifi.it meza@lse.ac.uk 


\section{Introduction}

Can a bank increase its profit by giving away money? This paper suggests this may occur, due to hidden information, in a monopolistic credit market. The result arises whenever the entry of worse, surplus-reducing, borrowers can be avoided by use of a subsidy to inactivity that the bank itself should pay. We show that under some conditions, notably a share of good entrepreneurs that is neither too large nor too small, the proposed subsidy is profitable for the bank. Specifically, when the share of good entrepreneurs is very large, bad entrepreneurs do not impact that much on profit in a pooling contract and therefore the subsidy is not profitable. Instead when the share of good entrepreneurs is too small there is no room for profitable contracts anyway (pooling or separating). When the subsidy policy is profitable, it is also Pareto improving and strictly increases the welfare of each agent. Under some conditions this policy is the only one delivering positive profits and therefore it also avoids the overall collapse of a lemons' credit market (Akerlof, 1970). Moreover the ability to grant the subsidy is clearly specific to a monopolistic credit market and therefore the realized surplus is always larger under monopoly than under competition.

The literature on the credit market has already discussed the possibility that a subsidy to stay out might increase welfare. Most contributions in this field generally suggest that a public subsidy may improve on the private equilibrium (see for example de Meza and Webb, 2000; Gruner, 2003). Reito (2011) considers both private and public interventions. In his paper, entrepreneurs may decide to join in a group and voluntarily collect and use their endowments as collateral to allow lenders to separate good from bad types. If their wealth is not enough, then government intervention is needed. Our idea, instead, is that a monopolistic bank itself can implement the subsidy policy and increase its profits.

\section{$2 \quad$ A simple model}

There is a large number, $N$, of potential entrepreneurs, each endowed with one of two possible projects, $a$ and $b$. Both projects require a fixed investment of $L$, but differ in their final expected gross (and net) return. Project $a$, the good one, succeeds with probability $p_{a}$ and yields $y_{a}$. Project $b$, the bad one, yields in case of success a return $y_{b}>y_{a}$, but with a probability $p_{b}<p_{a}$. 
Both projects deliver zero revenues in case of failure. Assume that project $a$ has a positive net value, while project $b$ a negative one, that is:

$$
p_{b} y_{b}<L<p_{a} y_{a}
$$

Accordingly, bad projects should not be undertaken, from a social perspective, as they produce less than the resources employed. But because of limited liability and asymmetric information they can still be financed at a common contract with better entrepreneurs and benefit from an implicit cross subsidy.

Potential entrepreneurs have no endowment, so they are forced to ask for outside finance. There is a single lender/bank with all the contractual power and trying to extract all possible surplus from its prospective borrowers. As regards the informational structure, each firm knows its own quality while the bank only knows the proportion of good types, $\alpha$. As in Innes (1991), assume that the final returns are imperfectly observable in the sense that the bank cannot verify the actual output produced. In this case, the optimal form of financing is the debt contract ${ }^{1}$. We assume universal risk neutrality and an infinitely elastic supply of funds at a risk-free interest rate normalized to 0 . A financial contract specifies the fixed loan size, $L$, and the sum that the firm has to repay if the final project is successful, $R^{2}$. As no endowment is available, the standard theory predicts that the bank will offer a pooling contract that specifies no collateral requirement and a repayment chosen to reap all the surplus. For a given pooling repayment sum $R$, firms' profits are

$$
\pi_{i}(R)=p_{i}\left(y_{i}-R\right), \quad i=a, b,
$$

where a borrower type- $i$ accepts the contract if $R \leq y_{i}$. Hence if $R>y_{a}$, only bad firms apply. The best choice for the bank is setting $R=y_{a}$ and proposing it as a the pooling contract if and only if $\pi_{\text {pool }}>0$ :

$$
\alpha \geq \frac{L-p_{b} y_{a}}{y_{a}\left(p_{a}-p_{b}\right)}=\alpha_{\text {pool }}
$$

If the proportion of good types is not high enough, that is if $\alpha<\alpha_{\text {pool }}$, all firms are credit rationed. In both cases the equilibrium is clearly inefficient

\footnotetext{
${ }^{1}$ As pointed out by de Meza and Webb (1987), if the final returns were perfectly observable, the bank could reach the optimum by offering a share finance contract.

${ }^{2}$ With full information, the optimal contractual terms would be $R=y_{a}$ for type $a$ and no contract for the inefficient type $b$. If $a$ accepts the contract, the monopolistic bank is able to attain its first-best profit, $p_{a} y_{a}-L$ (that is the project's expected value minus investment costs).
} 
from a social standpoint as project $a$ (only) delivers a positive net present value.

Now suppose that the lender can make a transfer, $G$, to induce bad types to stay out of the market. In this case the bank maximizes per-loan profits as follows:

$$
\max \alpha p_{a} R-G(1-\alpha)-\alpha L
$$

with the following incentive compatibility constraints

$$
\begin{aligned}
I C_{a}: & p_{a}\left(y_{a}-R\right)-G \geq 0, \quad \text { and } \\
I C_{b}: & p_{b}\left(y_{b}-R\right)-G \leq 0 .
\end{aligned}
$$

Solving $I C_{a}$ and $I C_{b}$, the repayment $R$ and the transfer required $G$ must satisfy:

$$
\begin{gathered}
R \leq \frac{p_{a} y_{a}-p_{b} y_{b}}{p_{a}-p_{b}}, \\
G \geq \frac{p_{a} p_{b}\left(y_{b}-y_{a}\right)}{p_{a}-p_{b}} .
\end{gathered}
$$

Of course the maximizing values of $R^{*}$ and $G^{*}$ are given by the equality constraints in (4). Substituting in (2) we obtain ${ }^{3}$

$$
\pi_{\text {sep }}=\alpha p_{a} y_{a}-G^{*}-\alpha L
$$

Proposition 1 Under conditions on the parameters values, there exists distributions of entrepreneurs (e.g. shares of good ones in the market, $\alpha$ ) for which the subsidy policy may be profitable for the bank. When this occurs the subsidy policy must be Pareto welfare improving on a pure interest-rate contract.

Let us compare both policies to find the range of $\alpha$ values such that $\pi_{\text {sep }} \geq \pi_{\text {pool }}$. We find that a necessary and sufficient condition is that

$$
\alpha \leq \frac{L\left(p_{a}-p_{b}\right)+p_{b}^{2} y_{a}-p_{a} p_{b} y_{b}}{\left(L-p_{b} y_{a}\right)\left(p_{a}-p_{b}\right)}
$$

\footnotetext{
${ }^{3}$ See the appendix.
} 
Equation (6) shows that the separating policy is profitable in general for comparatively low values of $\alpha$. Intuitively this is plausible: when the proportion of risky entrepreneurs is relatively small, the best policy for the bank is to accept their presence in the borrowers' pool. In this case, bad types will not impact too much on profits. Instead, when $\alpha$ is smaller, a subsidy to keep them out may make sense. Now define $\alpha^{*}$ as the threshold value for which the subsidy is more profitable. Clearly, condition (6) is relevant only if bank's profit is positive at $\alpha^{*}$. It is $\pi_{\text {pool }} \geq 0$ when

$$
\alpha \geq \frac{L-p_{b} y_{a}}{y_{a}\left(p_{a}-p_{b}\right)}
$$

while it is $\pi_{s e p} \geq 0$ when $^{4}$

$$
\alpha \geq \frac{p_{a} p_{b}\left(y_{b}-y_{a}\right)}{\left(p_{a} y_{a}-L\right)\left(p_{a}-p_{b}\right)}=\frac{G}{\left(p_{a} y_{a}-L\right)} .
$$

We define $\alpha_{\text {sep }}$ as the threshold value for which condition (8) is satisfied. To ensure that the subsidy policy is profitable we need the additional condition $\alpha_{\text {sep }} \leq \alpha^{*}$. We show that it is true if and only if ${ }^{5}$

$$
\frac{L\left(p_{b} y_{b}+p_{a} y_{a}-L\right)-p_{b} y_{b} p_{a} y_{a}}{L\left(p_{b} y_{a}+p_{a} y_{b}-L\right)-p_{b} y_{b} p_{a} y_{a}} \geq \frac{p_{b}}{p_{a}} .
$$

The term on the left-hand side of (9) is larger the lower is the difference between the projects. The term on the right-hand side is smaller the larger is the difference in the probabilities. Note that the repayment sum under the subsidy policy is lower than that under the pooling policy (this is a necessary condition for the $I C_{a}$ ). This implies that good types are necessarily better off under the subsidy policy. For $I C_{b}$, this is true also for bad types and clearly, from (6), for the bank as well. Hence the subsidy policy is Pareto improving. $Q E D$.

Proposition 2 Under a utilitarian welfare function the subsidy policy, when it is profitable for the bank, is the only one allowing full realization of potential surplus.

\footnotetext{
${ }^{4}$ See the appendix.

${ }^{5}$ See the appendix.
} 
Potential surplus, $\bar{W}$, in this market is the net surplus from the $a$-projects for any $\alpha$ :

$$
\bar{W}=\alpha N\left(p_{a} y_{a}-L\right)
$$

Considering that for $\alpha<\alpha_{\text {sep }}$, no credit contract is offered, for $\alpha_{\text {sep }} \leq$ $\alpha \leq \alpha^{*}$, the subsidy-contracts are offered, and for $\alpha>\alpha^{*}$, only the pooling contract is offered, the realized surplus in the three situations is respectively:

$$
\begin{gathered}
W=0 \text { for } \quad \alpha<\alpha_{\text {sep }} \\
W=\alpha N\left(p_{a} y_{a}-L\right) \text { for } \alpha_{\text {sep }} \leq \alpha \leq \alpha^{*} \\
W=N\left(\alpha p_{a} y_{a}+(1-\alpha) p_{b} y_{b}-L\right) \quad \text { for } \alpha>\alpha^{*}
\end{gathered}
$$

The potential surplus is realized only under the subsidy policy. $Q E D$.

Proposition 3 A competitive credit market can never achieve the potential surplus. For any value of $\alpha$, the realized surplus is (weakly) lower than the monopoly one.

A subsidy policy, necessarily requiring a cross-subsidy between contracts, can never be implemented in a competitive credit market. Hence the only contract available for banks is the pooling one. Banks will only offer credit for $\alpha>\alpha_{\text {pool }}$. And even in this case the pooling contract will be offered with realized welfare:

$$
\begin{array}{llll}
W & =0 & & \\
W & =N\left(\alpha p_{a} y_{a}+(1-\alpha) p_{b} y_{b}-L\right) & \text { for } & \alpha>\alpha_{\text {pool }}
\end{array}
$$

QED.

Proposition 4 For a range of parameters' values, a subsidy to inactivity can avoid the collapse of the credit market. 
An alternative way to look at the problem is to analyze the cases where the separating policy is profitable while the pooling one is not. For this to be true, the share of good borrowers in a separating equilibrium must be lower than the threshold in case of pooling, i.e.,

$$
\alpha_{\text {sep }}<\alpha_{\text {pool }}
$$

which is true when ${ }^{6}$ :

$$
\frac{L-p_{b} y_{b}}{L-p_{b} y_{a}}>\frac{L}{p_{a} y_{a}}
$$

This condition is more likely to be satisfied the smaller is the difference between $y_{b}$ and $y_{a}$, and the larger is the surplus of the good project. Whenever (13) holds, there exist values of $\alpha$ such that the separating policy is profitable while the pooling policy is not. Note that this case is relevant since the subsidy policy, by enlarging the contract space, avoids the collapse of the credit market. It is immediate that when $\alpha<\alpha_{\text {pool }}$, adverse selection normally produces the standard lemons' problem and no standard contract could be offered without the subsidy. Besides, in this case the subsidy policy is again Pareto improving. $Q E D$

\section{Concluding remarks}

In this paper we have shown that under some conditions, a monopolistic credit market may benefit from the enforcement of a policy subsidizing inactivity of the worse borrowers. The use of a subsidy (and the interest rate) as a sorting device allows the bank to offer credit only to good quality borrowers, thus increasing its profit. Separation necessarily implies a lower interest rate on credit. Worse borrowers enjoy the subsidy which, for incentive compatibility, must leave them with the same satisfaction as the separating credit contract. Note that by construction this latter contract, in practice a level of repayment, is necessarily better than the one offered in the no-subsidy contract. Hence when the conditions for profitability of the subsidy policy are met, the policy is also Pareto improving, and indeed it is the only policy allowing full realization of surplus under a utilitarian welfare function. This is in stark contrast with models of separation attained through collateral, where

\footnotetext{
${ }^{6}$ See the appendix.
} 
the use of collateral is actually a dead-weight cost for society as a whole, and generally decreases aggregate welfare (Coco, 2000). Note that the source of the overall increase in welfare is the fact that surplus-destroying projects are not carried out in equilibrium under the subsidy policy. Another interesting feature of this model is that under some conditions (e.g. for some values of $\alpha$ ) the subsidy policy is the only one avoiding total collapse of the credit market. Finally note that in a competitive credit market the subsidy policy is unavailable. The joint offer of the subsidy and contract is possible only for a pure monopolist (or a perfect cartel). Hence paradoxically a competitive market would collapse for a wider range of values of $\alpha$.And anyway, even if banks were able to grant loans, it could never prevent welfare-destroying entrepreneurs from carrying out their projects.

Of course the implementation of this policy meets some limits in the possibility that, enticed by the possibility of gaining the subsidy, any individual would apply for a loan. The subsidy thus would increase endogenously the share of would-be entrepreneurs without a proper project in the market. However the description of the credit market above is necessarily a simplified one. A basic evaluation on the investment project, possibly able to sort out the fake projects, is preliminarly performed at any lending institution.

Another limit of the analysis, but also an interesting feature, is the assumption of monopolistic banking. Although possibly unsuitable for most part of the developed world, this assumption seems more tenable in developing countries and even less densely populated areas in the developed world. Several past contributions have challenged the assumption of perfect competition in banking due to barriers to entry, structural regulation and sunk $\operatorname{costs}^{7}$. Moreover some more recent empirical investigations report evidence in support of the assumption of monopoly or of a cartel in the credit market. Cosimano and McDonald (1998) for example verify that public banks in the USA respond to an unanticipated decline in the marginal costs of loans with a much larger increase in the market value of equity. They show that this would occur when the loan rate is priced above the marginal costs of loan (feasible only in case of monopoly power). Moreover Beck et al. (2006) report that the bank concentration index is very high (more than 70\%) in most of the countries they survey.

At a more general level however our result suggests that in a lemons' market, screening by subsidy may increase overall welfare and avoid mar-

\footnotetext{
${ }^{7}$ See Klein (1971) and Monti (1972).
} 
ket collapse. To be feasible however this policy need a monopolistic market structure. In our opinion this contribution may open the road to more work on how to avoid the worst consequences of adverse selection. An interesting extension would be the possibility to compare the subsidy policy to an alternative arrangement fee constructed in the form of a reverse pre-screening mechanisms. Equally interesting is an extension to a moral hazard setting where the least motivated entrepreneurs could be deterred from becoming entrepreneurs more easily through a subsidy or a fee. 


\section{Appendix}

\subsection{Appendix A: Proofs}

\section{A) Proof of eq. (5)}

$$
\pi_{\text {sep }}=\alpha p_{a}\left(\frac{p_{a} y_{a}-p_{b} y_{b}}{p_{a}-p_{b}}\right)-(1-\alpha)\left(\frac{p_{a} p_{b}\left(y_{b}-y_{a}\right)}{p_{a}-p_{b}}\right)-\alpha L=
$$

simplifying:

$$
\begin{aligned}
& =\frac{\alpha p_{a}^{2} y_{a}-p_{a} p_{b} y_{b}+p_{a} p_{b} y_{a}-\alpha p_{a} p_{b} y_{a}-\alpha L p_{a}+\alpha L p_{b}}{\left(p_{a}-p_{b}\right)} \\
& =\frac{\alpha p_{a} y_{a}\left(p_{a}-p_{b}\right)-p_{a} p_{b}\left(y_{b}-y_{a}\right)-\alpha L\left(p_{a}-p_{b}\right)}{\left(p_{a}-p_{b}\right)}= \\
& =\alpha p_{a} y_{a}-\frac{p_{a} p_{b}\left(y_{b}-y_{a}\right)}{\left(p_{a}-p_{b}\right)}-\alpha L=\alpha p_{a} y_{a}-G-\alpha L
\end{aligned}
$$

B) Proof of (6):

We can show that:

$$
\begin{gathered}
\frac{\alpha p_{a} y_{a}\left(p_{a}-p_{b}\right)-\alpha L\left(p_{a}-p_{b}\right)-p_{a} p_{b}\left(y_{b}-y_{a}\right)}{p_{a}-p_{b}}>\alpha\left(p_{a} y_{a}-p_{b} y_{a}\right)+p_{b} y_{a}-L \\
\frac{\alpha\left[p_{a} p_{b} y_{a}-p_{b}^{2} y_{a}-L\left(p_{a}-p_{b}\right)\right]}{\left(p_{a}-p_{b}\right)}>\frac{p_{a} p_{b} y_{b}+p_{b}^{2} y_{a}-p_{a} L+p_{b} L}{p_{a}-p_{b}} \\
\frac{\alpha\left(L-p_{b} y_{a}\right)\left(p_{a}-p_{b}\right)}{\left(p_{a}-p_{b}\right)}<\frac{L\left(p_{a}-p_{b}\right)-p_{a} p_{b} y_{b}+p_{b}^{2} y_{a}}{p_{a}-p_{b}} \\
\alpha<\frac{L\left(p_{a}-p_{b}\right)+p_{b}^{2} y_{a}-p_{a} p_{b} y_{b}}{\left(L-p_{b} y_{a}\right)\left(p_{a}-p_{b}\right)}
\end{gathered}
$$

C) Proof of (8): 


$$
\begin{aligned}
\pi_{s e p} & =\alpha p_{a} y_{a}-\frac{p_{a} p_{b}\left(y_{b}-y_{a}\right)}{\left(p_{a}-p_{b}\right)}-\alpha L= \\
& =\frac{\alpha p_{a}^{2} y_{a}-\alpha p_{a} p_{b} y_{a}-\alpha p_{a} L+\alpha p_{b} L-p_{a} p_{b}\left(y_{b}-y_{a}\right)}{\left(p_{a}-p_{b}\right)}= \\
& =\frac{\alpha\left[\left(p_{a} y_{a}-L\right)\left(p_{a}-p_{b}\right)\right]-p_{a} p_{b}\left(y_{b}-y_{a}\right)}{\left(p_{a}-p_{b}\right)}
\end{aligned}
$$

thus the proportion of good type $(a)$ sufficient for positive profit in case of separating is:

$$
\alpha>\frac{p_{a} p_{b}\left(y_{b}-y_{a}\right)}{\left(p_{a} y_{a}-L\right)\left(p_{a}-p_{b}\right)}
$$

which is equal to:

$$
\alpha>\frac{G}{\left(p_{a} y_{a}-L\right)}
$$

\section{D) Proof of (9):}

From (6) and (8), we can show that $\alpha_{\text {sep }}<\alpha^{*}$ iff:

$$
\begin{gathered}
\frac{p_{a} p_{b}\left(y_{b}-y_{a}\right)}{\left(p_{a} y_{a}-L\right)\left(p_{a}-p_{b}\right)}<\frac{L\left(p_{a}-p_{b}\right)+p_{b}^{2} y_{a}-p_{a} p_{b} y_{b}}{\left(L-p_{b} y_{a}\right)\left(p_{a}-p_{b}\right)} \\
\frac{p_{a} p_{b}\left(y_{b}-y_{a}\right)}{\left(p_{a}-p_{b}\right)}<\frac{\left[L\left(p_{a}-p_{b}\right)+p_{b}^{2} y_{a}-p_{a} p_{b} y_{b}\right]\left(p_{a} y_{a}-L\right)}{\left(L-p_{b} y_{a}\right)\left(p_{a}-p_{b}\right)} \\
p_{a} p_{b} y_{b}-p_{a} p_{b} y_{a}<\frac{p_{a}^{2} y_{a} L-p_{a} L^{2}-p_{a} p_{b} y_{a} L+p_{b} L^{2}+p_{a} p_{b} y_{a}^{2}-p_{b}^{2} y_{a} L-p_{a}^{2} p_{b} y_{a} y_{b}+p_{a} p_{b} y_{b} L}{\left(L-p_{b} y_{a}\right)} \\
p_{a} p_{b} y_{b}-p_{a} p_{b} y_{a}<\frac{p_{a}^{2} y_{a} L-p_{a} L^{2}-p_{a}^{2} p_{b} y_{a} y_{b}+p_{a} p_{b} y_{b} L}{\left(L-p_{b} y_{a}\right)}-\frac{p_{a} p_{b} y_{a}\left(L-p_{b} y_{a}\right)}{\left(L-p_{b} y_{a}\right)}+\frac{p_{b} L\left(L-p_{b} y_{a}\right)}{\left(L-p_{b} y_{a}\right)} \\
p_{b}\left(p_{a} y_{b}-L\right)<\frac{p_{a} L\left(p_{a} y_{a}-L\right)-p_{a} p_{b} y_{b}\left(p_{a} y_{a}-L\right)}{\left(L-p_{b} y_{a}\right)} \\
p_{b}\left(p_{a} y_{b}-L\right)<\frac{p_{a}\left(p_{a} y_{a}-L\right)\left(L-p_{b} y_{b}\right)}{\left(L-p_{b} y_{a}\right)}
\end{gathered}
$$

Thus:

$$
\frac{\left(p_{a} y_{b}-L\right)}{\left(p_{a} y_{a}-L\right)}<\frac{p_{a}}{p_{b}} \frac{\left(L-p_{b} y_{b}\right)}{\left(L-p_{b} y_{a}\right)}
$$


which can then be easily rewritten as (9).

\section{E) Proof of (13):}

Given (7) and (8), we can show that $\alpha_{\text {sep }}<\alpha_{\text {pooling }}$ if and only if:

$$
\begin{gathered}
\frac{G}{\left(p_{a} y_{a}-L\right)}<\frac{L-p_{b} y_{a}}{y_{a}\left(p_{a}-p_{b}\right)} \\
\frac{p_{a} p_{b}\left(y_{b}-y_{a}\right)}{\left(p_{a}-p_{b}\right)}<\frac{\left(L-p_{b} y_{a}\right)\left(p_{a} y_{a}-L\right)}{y_{a}\left(p_{a}-p_{b}\right)} \\
p_{b} y_{b}<\frac{p_{a} y_{a} L-L^{2}+p_{b} y_{a} L}{p_{a} y_{a}} \\
p_{b} y_{b}-L<\frac{p_{b} y_{a} L-L^{2}}{p_{a} y_{a}} \\
L-p_{b} y_{b}>\frac{L^{2}-p_{b} y_{a} L}{p_{a} y_{a}} \\
\frac{L-p_{b} y_{b}}{L}>\frac{L-p_{b} y_{a}}{p_{a} y_{a}}
\end{gathered}
$$

Thus as shown in (13):

$$
\frac{L-p_{b} y_{b}}{L-p_{b} y_{a}}>\frac{L}{p_{a} y_{a}}
$$




\subsection{Appendix B: Numerical Example}

To illustrate quantitatively the significance of subsidizing inactivity, we propose a numerical analysis. Our baseline exercise assumes that the project succeeds with probability $p_{a}$ and $p_{b}$ respectively 0.7 and 0.3 while the gross return $y$ is 8 for the $a$-good type and 9 for the $b$-bad one. The size of the loan $L$ is equal to 4 . The numerical simulation reports conditions on the share of (good) entrepreneurs which are consistent with the general theoretical features proposed in this note. Specifically we observe that when a share $\alpha$ is higher than 0.5 , then lender's profit in case of pooling $\left(\pi_{\text {pooling }}\right)$ is positive. In the separating case according to the incentive constraints (eq. 3-4), the threshold $\alpha$ required to realize positive profits $\left(\alpha_{\text {sep }}\right)$ is 0.32 . A graphical comparison of the two policies (in terms of expected returns) is proposed below. First, this result suggests that under the values chosen there is no possibility for a pooling contract when the share of good types is lower than 0.5, because the market collapses. Instead (as shown in the graph) if the value is lower than 0.32 there is no space for any positive profit (pooling or separating) contract. However in the case where $\alpha$ lies between 0.32 and 0.5 , the policy of subsidizing inactivity is profitable for the bank (red line in the figure) and it is also the only feasible profitable contract. Further, applying (6), we find that the separating policy still dominates the pooling one even in case of $\alpha^{\prime} s$ higher than 0.5 until a $\alpha$-threshold of 0.67 . From 0.67 on, the proportion $\alpha$ of good entrepreneurs is so high that there is no need to subsidize bad type to stay out (low level of cross-subsidization). In the figure below we plot (only positive) profits for the pooling and the separating contracts (respectively blue and red) against values of $\alpha$, confirming the results above. 
Figure A1. Monopolist profits with different policies

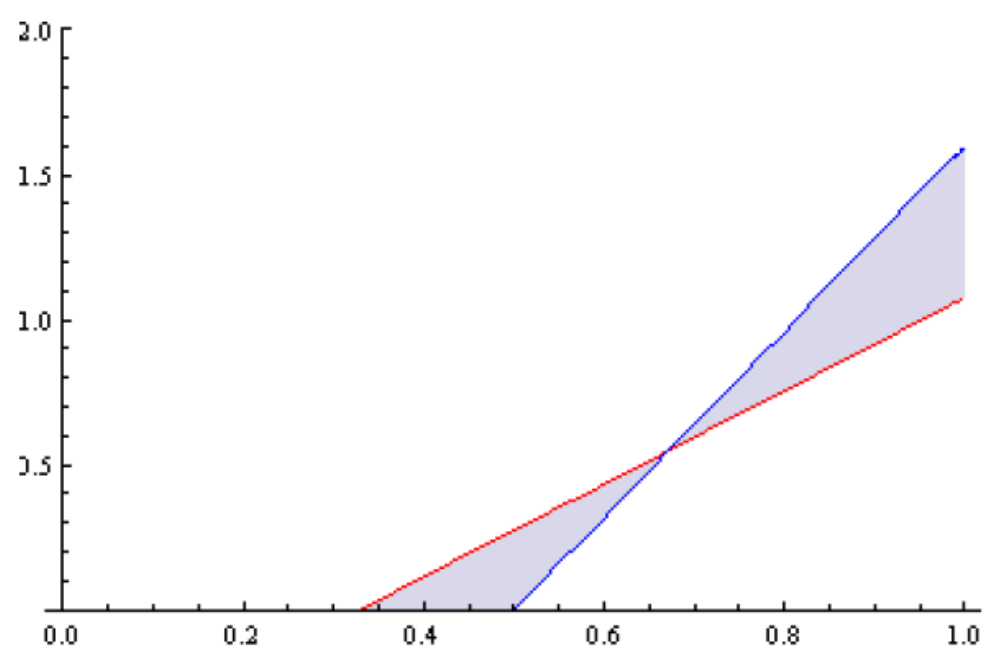

As regards the welfare comparison, the expected utility of an $a$-type in case of pooling is zero (the whole surplus is extracted due to the crosssubsidization), while the expected utility of a $b$-type is 0.3 . These amounts of surplus are reaped only in case the bank offers the pooling contract, which by the way occurs if $\alpha>0.67$. The surplus as a result of the offer of the separating contracts is instead equal to 0.525 for both types (so they are both better off relative to the pooling case), and is actually realized for $0.32<\alpha<0.67$. In Figure A2 below we plotted the aggregate surplus in a market with 100 potential entrepreneurs $(N)$ against the proportion of good entrepreneurs, $\alpha$. The red line is the maximum potential surplus attainable under symmetric information (see eq 10), and is obtained assuming that only good entrepreneurs carry out their projects. The broken blue line is obtained calculating and summing up the welfare actually obtained by the three types of agents, taking into account the contracts actually offered by a profit maximizing monopolist bank at each value of $\alpha$ (see eqn.s $10^{\prime}$ ). It is immediate that the maximum potential surplus is realized only for intermediate values of $\alpha$, where the monopolist bank offers the separating contract. A competitive bank can only offer the pooling contract for $\alpha>0.5$. In the Figure the competitive welfare is the green line. Also in this case it is immediate that it lies entirely below the welfare realized under monopoly. 
Figure A2. Surplus:potential and realized

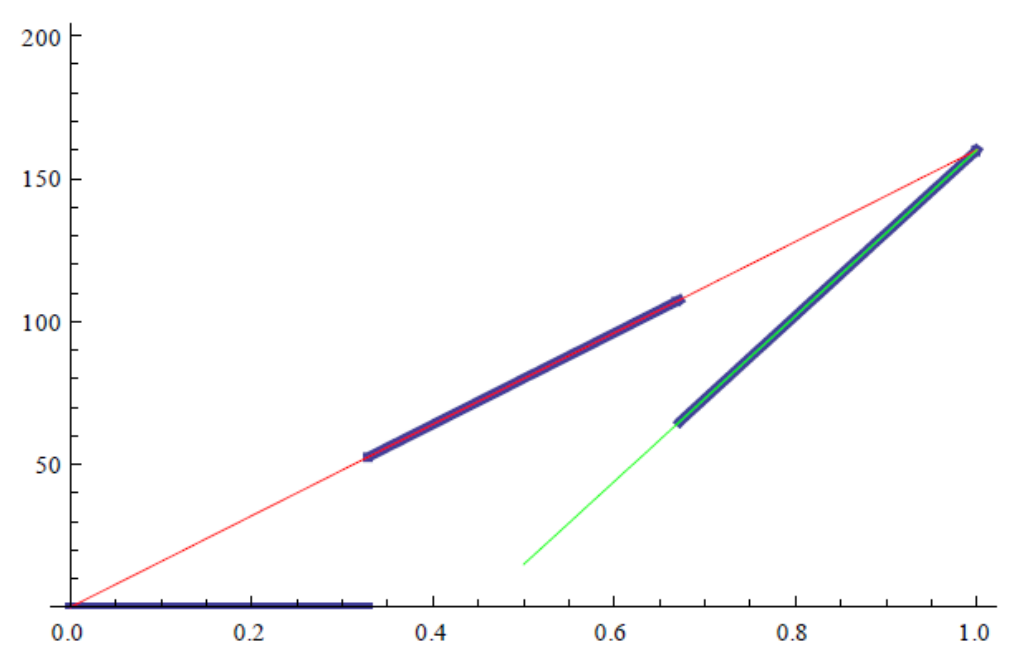




\section{References}

[1] Akerlof, G. (1970), "The Market for 'Lemons': Quality Uncertainty and the Market Mechanism", Quarterly Journal of Economics, 84 (3), pp. $488-500$

[2] Beck, T., Demirguc-Kunt, A. and Levine, R. (2006), "Bank Concentration, Competition and Crises: First Results", Journal of Banking and Finance 30, pp. 1581-1603

[3] Coco, G. (2000), "On the Use of Collateral", Journal of Economic Surveys, 14 (2), pp. 191-214

[4] Cosimano, T. and McDonald, B. (1998), "What's different among banks?", Journal of Monetary Economics, 41, pp. 57-70

[5] de Meza, D. and Webb, D. (1987), "Too Much Investment: A Problem of Asymmetric Information", Quarterly Journal of Economics, 102 (2), pp. 281-292

[6] de Meza, D. and Webb, D. (2000), "Does Credit Rationing Imply Insufficient Lending?", Journal of Public Economics, 78 (3), pp. 215-234

[7] Gruner, H. (2003), "Redistribution as a selection device", Journal of Economic Theory, 108, pp. 194-216

[8] Klein, B. (1971), "Competitive interest rates payments on bank deposits and the long-run demand for money", American Economic Review, 64, pp. $931-949$

[9] Innes, R. (1991), "Investment and Government Intervention in Credit Markets when there is Asymmetric Information", Journal of Public Economics, 46, pp. 347-381.

[10] Monti, M. (1972). 'Deposits, credit and interest rates determination under alternative bank objectives.' In G. Szego and K. Shell, eds., Mathematical Methods in Investment and Finance, pp.431-454, Amsterdam. North-Holland

[11] Reito, F. (2011), "Redistribution, Collateral Subisidy and Screeening", FinanzaArchiv, 67, pp. 8-26 


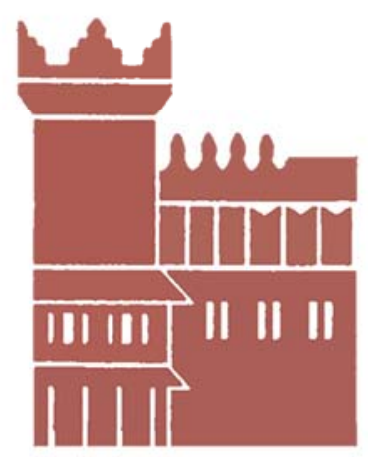

Alma Mater Studiorum - Università di Bologna DEPARTMENT OF ECONOMICS

Strada Maggiore 45

40125 Bologna - Italy

Tel. +39051 2092604

Fax +390512092664

http://www.dse.unibo.it 